\title{
Detection of Trehalose Monomycolate in Mycobacterium leprae Grown in Armadillo Tissues
}

\author{
By KULDEEP R. DHARIWAL, ${ }^{1}$ YI-MING YANG,${ }^{2} \dagger$ HENRY M. FALES ${ }^{2}$ \\ AND MAYER B. GOREN ${ }^{1,3 *}$ \\ ${ }^{1}$ Department of Molecular and Cellular Biology, National Jewish Center for Immunology and \\ Respiratory Medicine, Denver, Colorado 80206, USA \\ ${ }^{2}$ National Heart and Lung Institute, National Institutes of Health, Bethesda, Maryland, USA \\ ${ }^{3}$ Department of Microbiology and Immunology, University of Colorado Health Sciences Center, \\ Denver, Colorado, USA
}

(Received 20 May 1986; revised 19 August 1986)

Trehalose-6-monomycolate (TMM) was isolated from the lipids of armadillo-derived Mycobacterium leprae. Only meagre amounts of this glycolipid were recovered, but its structure was unequivocally established. Only $\alpha$-mycolates were detected in the TMM by ${ }^{25}{ }^{2} \mathrm{Cf}$ plasma desorption mass spectrometry. Electron impact mass spectrometry showed the alpha branch to be principally $\mathrm{C}_{20}$. Trehalose dimycolate (cord factor) was not detectable. Since we have also found TMM in $M$. lepraemurium and in every Mycobacterium species so far examined, we suggest that this glycolipid is truly ubiquitous amongst mycobacteria.

\section{INTRODUCTION}

Mycolate esters of trehalose should be ubiquitous amongst Mycobacterium species. The thesis has its origin in studies by Walker et al. (1973) on the biosynthesis of corynomycolic acid by Corynebacterium diphtheriae. This low-molecular-mass (32-carbon) alpha-branched $\beta$-hydroxy acid has been a useful model (Gastambide-Odier \& Lederer, 1964) for studying late steps in the biosynthesis of the much more complex mycolic acids of mycobacteria (60 to 90 carbons), which are also alpha-branched, $\beta$-hydroxy acids (for reviews see Goren $\&$ Brennan, 1979; Minnikin, 1982; Takayama \& Qureshi, 1984). According to Walker et al. (1973), a cell-free extract from $C$. diphtheriae condensed two molecules of $\left[1^{-14} \mathrm{C}\right]$ palmitate via a Claisen-type condensation to produce 2-tetradecyl-3-keto-octadecanoic acid, which they reduced chemically to a mixture of erythro and threo corynomycolic acids:

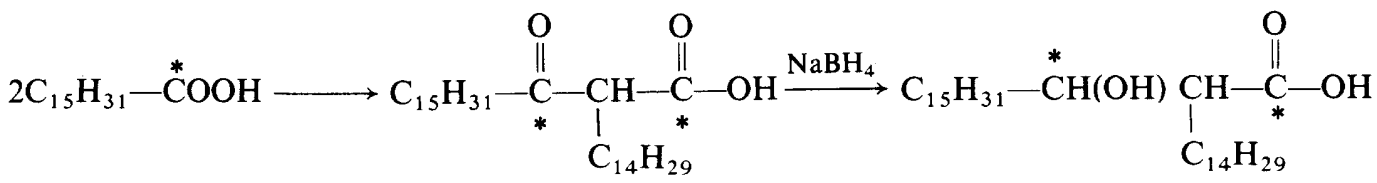
erythro/threo corynomycolic acid

On the other hand, when $C$. diphtheriae in culture condensed the labelled palmitate, the intermediate keto acid was immediately incorporated into a 6-monoester of trehalose, which was subsequently reduced biologically to trehalose-6-corynomycolate (Promé et al., 1974; Ahibo-Coffy et al., 1978). It seems likely that this sequence is also valid for mycobacteria.

\footnotetext{
† Visiting Scientist from Shanghai Institute of Materia Medica, Academia Sinica, China.

Abbreviations: MAT, trehalose-6-monoacetate-6'-monomycolate; TDM, trehalose-6,6'-dimycolate (cord factor); TMM, trehalose-6-monomycolate; TMS, $O$-trimethylsilyl.
} 
Accordingly the completely assembled carbon skeleton of mycobacterial mycolic acid might also be expected to appear immediately as a trehalose derivative, potentially the precursor of trehalose-6-mycolate (TMM) (Kato \& Maeda, 1974) and therefore of 'cord factor', trehalose6,6'-dimycolate (TDM) (Kilburn et al., 1982) (for reviews see Asselineau \& Asselineau, 1978; Lederer, 1976, 1984).

If all of the mycolic acid synthesized by mycobacteria accumulated as trehalose derivatives, then the steady-state levels of these glycolipids and their contained mycolic acids would be enormous. In fact, they are meagre. Instead the bulk of the mycolic acids are found mainly esterified to the mycobacterial cell wall arabinogalactan (Azuma \& Yamamura, 1963; Kanetsuna et al., 1969; Bruneteau \& Michel, 1968; Vilkas \& Markovits, 1968). One may speculate from the studies just reviewed that the principal function of trehalose mycolates is to serve, either as such or as intermediates, to carry newly synthesized mycolic acid for transfer to growing cell wall. Indeed, important evidence in support of a trehalose mycolate 'carrier', potentially implicating trehalose-6-monoacetate-6'-monomycolate ('MAT') in this function was described by Takayama \& Armstrong (1976). Mycobacterium tuberculosis H37Ra incorporated [ $\left.{ }^{14} \mathrm{C}\right]$ acetate to produce MAT labelled in the mycolate moiety. After a chase with unlabelled acetate the radiolabel of this glycolipid declined with time and appeared instead in cell-wall-associated mycolate. It seems reasonable to anticipate, therefore, that all mycobacteria synthesize mycolic acid and incorporate it into cell wall via trehalose mycolate intermediates.

TMM was recently shown to be a direct precursor of TDM (Kilburn et al., 1982), and TDM has already been found in Mycobacterium lepraemurium from bacteria grown in vivo (Goren et al., 1979) as well as from those cultured in cell-free medium (Nakamura et al., 1984). In anticipation that TMM might be the central substance leading from newly synthesized mycolic acid to cell wall and to TDM, our efforts targeted on finding and identifying these extractable glycolipids in Mycobacterium leprae. TMM had thus far evidently not been sought, whilst TDM had heretofore eluded detection in only this Mycobacterium species (Minnikin et al., 1985). These glycolipids therefore represented a 'missing link', whose discovery could nevertheless be confidently expected based on the premises developed above.

\section{METHODS}

Lipids. A preparation designated 'crude $M$. leprae lipids' was kindly supplied to us by Dr P. J. Brennan. It was obtained from purified $M$. leprae recovered from irradiated infected armadillo livers (Draper, 1979; Hunter \& Brennan, 1981). Lyophilized bacilli were extracted with $2: 1(\mathrm{v} / \mathrm{v}) \mathrm{CHCl}_{3} / \mathrm{CH}_{3} \mathrm{OH}$ at $50^{\circ} \mathrm{C}$ for $15-18 \mathrm{~h}$. Partitioning according to Folch et al. (1957) and recovery of the material from the $\mathrm{CHCl}_{3}$ phase afforded the 'crude' product. Dr Philip Draper (National Institute for Medical Research, Mill Hill, London, UK) also kindly gave us $9.5 \mathrm{mg}$ of 'wall lipids' isolated by $1: 1(\mathrm{v} / \mathrm{v}) \mathrm{CHCl}_{3} / \mathrm{CH}_{3} \mathrm{OH}$ extraction of purified cell walls from $M$. leprae (Draper, 1976).

Column chromatography and TLC. The 'crude M. leprae lipids' (see above) were subjected to column chromatography to seek enrichment of TMM or TDM; this was successful only with this sample. Short columns packed with Whatman DE23 DEAE-cellulose and CF1 long-fibre cellulose $(1: 2, \mathrm{w} / \mathrm{w})$ were used in the neutralized acetate form (Goren, 1970 a). As summarized in Fig. 1,81 mg of the lipids were loaded in and washed with diethyl ether, and were eluted with diethyl ether/methanol $(70: 30, v / v)$. Fractions were monitored by TLC, and TMM-enriched fractions were combined for further enrichment. Sybron-Brinkmann Sil G-25 plates were used for analytical TLC. Plates were sprayed with $60 \%(\mathrm{w} / \mathrm{w}) \mathrm{H}_{2} \mathrm{SO}_{4}$ containing $0.01 \%$ orcinol and heated at $130{ }^{\circ} \mathrm{C}$ for 4-5 min. TMM and TDM spots assume a characteristic clean blue-grey colour in this treatment (Dhariwal et al., 1984). Samples of synthesized TMM (Liav \& Goren, 1984) and TDM (Liav \& Goren, 1980) were used as markers.

Preparative TLC of the considerably enriched material obtained from the DEAE-cellulose chromatographies was done on Sybron-Brinkmann $5 \mathrm{~cm}$ plates, developed successively in three solvent systems as described by P. Draper (personal communication): chloroform/methanol $(90: 10, \mathrm{v} / \mathrm{v}) 15 \mathrm{~cm}$; chloroform $/$ methanol/ $\mathrm{H}_{2} \mathrm{O}$ $(14: 6: 1$, by vol.) $10 \mathrm{~cm}$; and hexane/ether/acetic acid $(80: 18: 2$, by vol.) to the top of the plate (air dried after each development). The region containing TMM, visualized with iodine, was recovered and extracted with chloroform/methanol/ $\mathrm{H}_{2} \mathrm{O}(80: 20: 0.5$, by vol. $)$ and the recovered lipids were re-extracted into wet diethyl ether. As judged from its IR spectrum (see below) the recovered TMM still contained some impurity, partially removed by extracting with hexane and then with $\mathrm{CH}_{3} \mathrm{OH}$. The methanol-insoluble lipids (about $400 \mu \mathrm{g}$ ) appeared to be almost pure TMM. For IR examination, neat samples of lipids were deposited on a $\mathrm{NaCl}$ microplate, and examined in a Beckman IR-9 spectrophotometer with beam condenser. The IR spectra of TMM and TDM are 
Armadillo-derived $M$. leprae $(800-1000 \mathrm{mg})$

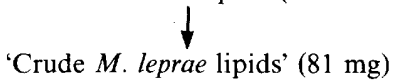<smiles>[3H][3H]</smiles>

, Cellulose/DEAE-cellulose $(2: 1, \mathrm{w} / \mathrm{w})$ chromatography $\mid$ (twice)

Load in ether; elute with ether/methanol $(7: 3, \mathrm{v} / \mathrm{v})$

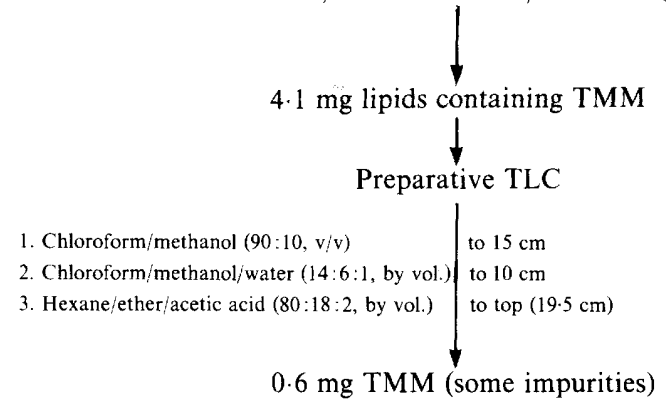

Fig. 1. Isolation of TMM from Folch-washed 'crude $M$. leprae lipids'. About $1 \mathrm{~g}$ (dry wt) armadilloderived $M$. leprae were extracted with $\mathrm{CHCl}_{3} / \mathrm{CH}_{3} \mathrm{OH}(2: 1, \mathrm{v} / \mathrm{v})$ at $50{ }^{\circ} \mathrm{C}$. After washing with Folch upper phase the lipids in the $\mathrm{CHCl}_{3}$ phase were chromatographed twice on cellulose/DEAE-cellulose $(2: 1, w / w)$. TMM from this enriched product was further separated by preparative TLC on silica gel plates by development with the three solvent systems shown and air drying between each development. About $0.6 \mathrm{mg}$ TMM (still impure) was recovered from $81 \mathrm{mg}$ 'crude $M$. leprae lipids'. It could be purified further by extractions with hexane followed by methanol and by HPLC.

very similar and possess unique features described below (Noll \& Bloch, 1955; Noll et al., 1956; Goren \& Brokl, 1974).

HPLC. To remove stubbornly persistent contaminants from the isolated TMM, HPLC separation was kindly done for us by Dr K. Takayama and colleagues, who had earlier established the conditions for separating and isolating small amounts of TMM and TDM from cell-free reaction systems. The apparatus and conditions for further purifying about $500 \mu \mathrm{g}$ of our nearly purified TMM were exactly as described before (Kilburn et al., 1982); semi-synthetic TMM was used to calibrate the system.

Mass spectrometry. ${ }^{252} \mathrm{Cf}$ plasma desorption mass spectra were obtained on an instrument (see Macfarlane, 1983) which was built for the National Institutes of Health by Professor R. Macfarlane of Texas A\&M, and subsequently modified by $\mathrm{L}$. Pannell to change samples automatically. Samples dissolved in polar solvents were applied to the conductive surface of an aluminized Mylar film in a sample holder either by evaporation or electrospraying (see above reference). The sample holder was then placed (through a vacuum lock) in front of a ${ }^{252} \mathrm{Cf}$ source [about $10 \mu \mathrm{Ci}(370 \mathrm{kBq})$ ]. The chamber is maintained at about $10^{-6} \operatorname{Torr}(\sim 1 \mathrm{mPa})$. Very high energy particles from the $\mathrm{Cf}$ source $(100 \mathrm{MeV})$ impinge on the sample to generate a plasma containing desorbed molecules with attached sodium cations and these are accelerated down a $42 \mathrm{~cm}$ flight tube by a $10 \mathrm{kV}$ grid. Flight times, which are proportional to the square root of the mass are stored in a computer and converted into masses. Each such ion is collected and added to others in the same channel to provide the mass spectrum. This mode of operation is useful principally to determine the molecular masses of the compounds under investigation.

In contrast, electron impact mass spectrometry with high temperature of the probe to volatilize the sample is useful for studying much less polar substances, i.e. lipid esters and permethylation products. It gives rise to fragments whose composition provides data about the intimate structure of the parent molecule (see, for example, Goren \& Brennan, 1979).

Permethylation analysis. A portion of almost pure TMM from $M$. leprae was used for permethylation analysis to establish the position of the mycolate ester. In this technique, the free hydroxyl groups in the acylated trehalose are methylated, the product is hydrolysed with base to free the esterified hydroxyl(s) and the resulting methylated sugar is separated from the waxy mycolic acid and identified (see Noll et al., 1956; Goren, 1970 b). For the permethylation about $200 \mu \mathrm{g}$ lipid was dissolved in $0.3 \mathrm{ml}$ methylene chloride; $50 \mu \mathrm{l}$ 2,6-di-tert-butyl pyridine and $50 \mu \mathrm{l}$ methyl trifluoromethanesulphonate were added and the mixture was held overnight in a bath at $60^{\circ} \mathrm{C}$, under reflux. The mixture was evaporated under $\mathrm{N}_{2}$, dissolved in ethyl acetate, washed with dilute $\mathrm{HCl}$, aqueous 


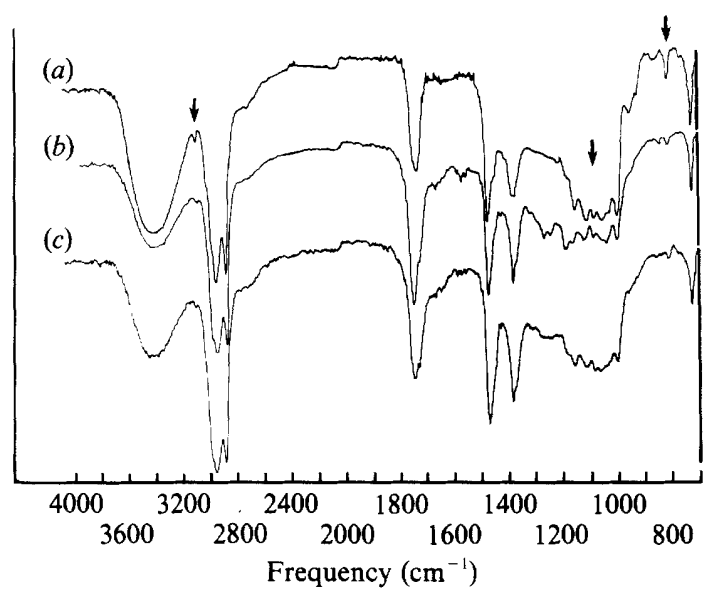

Fig. 2. IR spectra of TMM samples: (a) semi-synthetic, (b) from $M$. lepraemurium and (c) from $M$. leprae. Neat samples were deposited on a $\mathrm{NaCl}$ microplate and spectra obtained in a Beckman IR-9 spectrophotometer with beam condenser. Arrows point to specific absorption bands associated with $x$ mycolates $\left(3080 \mathrm{~cm}^{-1}\right)$, trehalose $\left(808 \mathrm{~cm}^{-1}\right)$, and trehalose 6-esters $\left(1000-1200 \mathrm{~cm}^{-1}\right)$. The IR spectra of three individual $M$. leprae TMM preparations were similar.

bicarbonate and $\mathrm{H}_{2} \mathrm{O}$, and the product was recovered. Our recent experiences with this elegant method described by Arnarp \& Lönngren (1978) prove it to give high levels of methylation without inducing either hydrolysis or acyl migration (Liav \& Goren, 1986).

Identification of the permethylated carbohydrate. (a) Alkaline hydrolysis of the permethylated TMM and separation of the methylated sugar from the K-mycolate were done as described by Noll et al. (1956). The methylated trehalose, dissolved in aqueous methanol, was then deionized with Bio-Rad mixed-bed resins and recovered.

(b) Acid hydrolysis. A portion of the (hepta-O-methyl) trehalose was dissolved in about $0.3 \mathrm{ml} 2 \mathrm{M}-\mathrm{HCl}$, sealed in a small tube and heated at $95^{\circ} \mathrm{C}$ for $18 \mathrm{~h}$ to hydrolyse the methylated sugar. The aqueous $\mathrm{HCl}$ was gently evaporated at about $40-50{ }^{\circ} \mathrm{C}$ with a stream of $\mathrm{N}_{2}$; the residue was deionized after dissolving in water and taken to dryness again.

(a) GLC was used to identify both the methylated trehalose and the scission products obtained from it by acid hydrolysis. The methylated trehalose was examined without derivatization by GLC $(2 \mathrm{~mm} \times 183 \mathrm{~cm}$ column of $\mathrm{SE} 30$ at $200^{\circ} \mathrm{C}, \mathrm{N}_{2}$ carrier gas at $30 \mathrm{ml} \mathrm{min}^{-1}$ ) and compared with an authentic sample of 2,3,4,6,2, $\mathbf{3}^{\prime}, 4^{\prime}$-hepta-Omethyl trehalose (see Kato \& Maeda, 1974; Goren et al., 1976). After acid hydrolysis (as above) the products [as the $O$-trimethylsilyl (TMS) derivatives] were also examined by GLC $\left(\mathrm{SE} 30,125^{\circ} \mathrm{C}\right)$ using authentic TMS derivatives of 2,3,4-tri- $O$-methyl glucose and of 2,3,4,6-tetra- $O$-methyl glucose for comparison (Goren et al., 1976; Liav \& Goren, 1986).

\section{RESULTS}

Preliminary examination of P. Draper's 'wall lipids' (see Methods) by TLC gave no evidence that these contained either TDM or TMM. [We did not search for MAT, but having recently synthesized this rare diester (Liav \& Goren, 1986) we plan in the future to search for evidence of MAT amongst various lipid extracts.] The more abundant 'crude $M$. leprae lipids' contained detectable amounts of what appeared to be TMM, but not of TDM.

Fig. 1 summarizes the procedures detailed in Methods for isolation of the 'enriched TMM'. Its IR spectrum is given in Fig. 2, in which the presumed TMM from $M$. leprae is compared with a like material obtained from crude lipids (kindly given to us by Dr P. Draper; see Draper \& Rees, 1973 , for their isolation) of in vivo grown (mice) M. lepraemurium (K. Dhariwal \& M. Goren, unpublished results) and with semi-synthetic TMM. Clearly all of the absorption frequencies characteristic of trehalose monomycolate (arrowed) are found in the two products from the in vivo-derived bacteria : $3080 \mathrm{~cm}^{-1}$ [cyclopropane of the 'alpha-type' mycolic acids (GastambideOdier et al., 1964)]; $808 \mathrm{~cm}^{-1}$ [a weak band specifically associated with trehalose (Goren, 


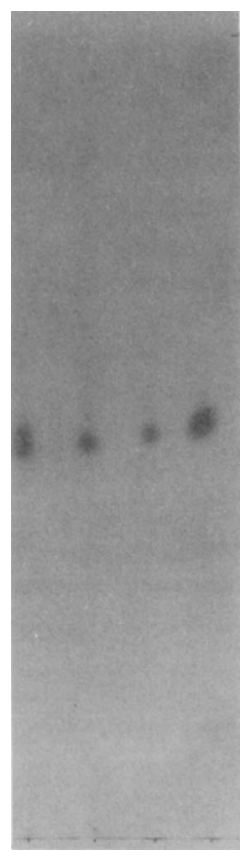

(a) (b) (c) (d)

Fig. 3

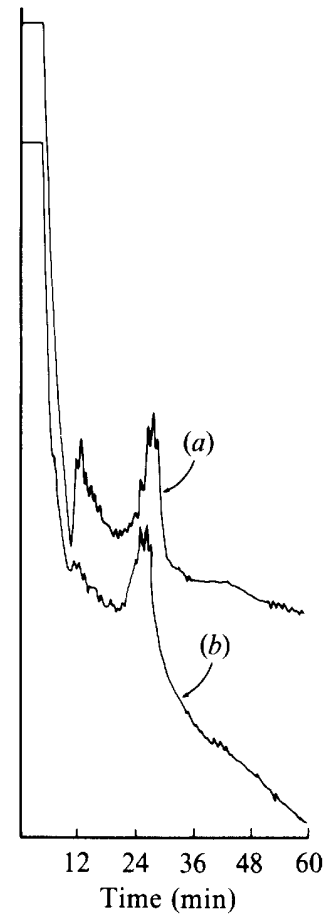

Fig. 4

Fig. 3. TLC of TMM samples in $\mathrm{CHCl}_{3} / \mathrm{CH}_{3} \mathrm{OH} / \mathrm{H}_{2} \mathrm{O}(75: 25: 4$, by vol.): (a) semi-synthetic, (b) from $M$. leprae, $(c)$ from $M$. lepraemurium and $(d)$ from $M$. microti. The spots were visualized by spraying the plate with $60 \%(\mathrm{w} / \mathrm{w}) \mathrm{H}_{2} \mathrm{SO}_{4}$ containing $0.01 \%$ orcinol and heating at $130{ }^{\circ} \mathrm{C}$ for $4-5 \mathrm{~min}$. TMM assumes a characteristic blue-grey colour after this treatment.

Fig. 4. HPLC elution curves of TMM samples: (a) semi-synthetic and (b) from M. leprae. M. leprae TMM prepared as outlined in Fig. 1 was purified further on a Waters Associates Radial-pak $C_{18}$ cartridge using a linear gradient of $0-60 \%$ hexane/2-propanol $(2: 1, \mathrm{v} / \mathrm{v})$ in 2-propanol/water $(9: 1, \mathrm{v} / \mathrm{v})$ at a flow rate of $2 \mathrm{ml} \mathrm{min}^{-1}$. Fractions were collected at $1 \mathrm{~min}$ intervals after $6 \mathrm{~min}$. The peaks at $25 \cdot 2$ and $26.3 \mathrm{~min}$ were the major peaks and nearly correspond to peaks obtained from the semi-synthetic TMM.

$1970 \mathrm{a})$ ]; and a succession of about seven peaks between 1000 and $1200 \mathrm{~cm}^{-1}$ highly characteristic of trehalose 6-esters (Goren \& Brokl, 1974). The spurious peaks in the region $1200-1400 \mathrm{~cm}^{-1}$ found in the spectrum of the product from $M$. lepraemurium indicate that it requires further purification. Fig. 3 shows a thin-layer chromatogram which compares the semisynthetic TMM with the samples derived from M. lepraemurium and $M$. leprae and with a quite pure TMM that we isolated in abundance from $M$. microti (K. R. Dhariwal et al., unpublished results).

To obtain a still purer sample, HPLC was carried out on about $400 \mu \mathrm{g}$ of the $M$. leprae glycolipid (Fig. 4). The peaks at 25.2 and $26.3 \mathrm{~min}$ were very close to the principal peaks obtained for the semi-synthetic TMM sample. The effluents corresponding to the two peaks were combined and used for studying the composition of the mycolate components by electron impact mass spectrometry (see below).

\section{${ }^{252} \mathrm{Cf}$ plasma desorption mass spectrometry}

Application of this technique to the semi-synthetic TMM (Fig. 5) allowed us to establish favourable conditions for obtaining informative spectra. Yet the quality of the spectra depends on variables that are often difficult to control or to recognize: in our interpretation the nature of 


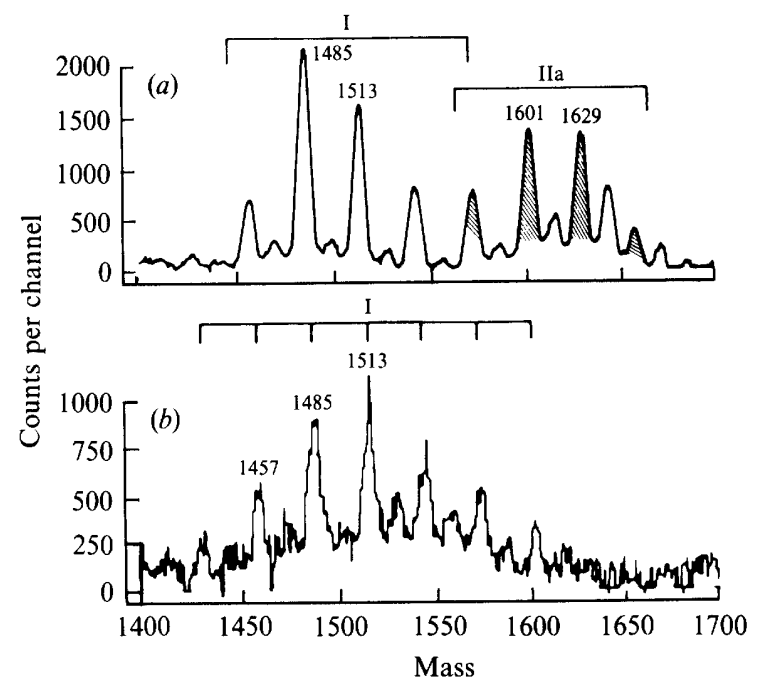

Fig. 5. ${ }^{252} \mathrm{Cf}$ plasma desorption mass spectra of trehalose monomycolates: $(a)$ semi-synthetic and $(b)$ from $M$. leprae. The semi-synthetic sample shows the presence of type I (dicyclopropane) and type IIa (methoxy) mycolates. Only type I are discernible in the spectrum of the $M$. leprae glycolipid.

the film sample produced by spraying was of critical importance, but was not consistently controllable. For example, successive samples formed from the semi-synthetic TMM in solution in acetone $/ \mathrm{CH}_{3} \mathrm{OH}$ or in $\mathrm{CHCl}_{3} / \mathrm{CH}_{3} \mathrm{OH}$ gave recognizable but nevertheless rather poor spectra during runs lasting $800 \mathrm{~min}$ each. In contrast, the spectrum in Fig. 5(a) was obtained during a 30 min scan from a (presumably identical) film also deposited from $\mathrm{CHCl}_{3} / \mathrm{CH}_{3} \mathrm{OH}$ solution. With the much scarcer sample from $M$. leprae (also sprayed onto the Mylar from a $\mathrm{CHCl}_{3} / \mathrm{CH}_{3} \mathrm{OH}$ solution) the spectrum in Fig. 5(b) was obtained during $5435 \mathrm{~min}$. Nevertheless, it is an unequivocal spectrum. It was the only one successfully obtained with our limited sample.

The scan in Fig. 5(a) shows that the semi-synthetic TMM is characterized by two prominent series of mycolate substituents that are identified as types I and IIa according to the scheme of D. E. Minnikin (Davidson et al., 1982). The series of type I are of the (cis,cis) dicylopropane types, also referred to as 'alpha' mycolates (see below and reviews mentioned earlier). The IIa series (shaded peaks) contain a methoxyl group with an adjacent methyl branch as depicted by the structure

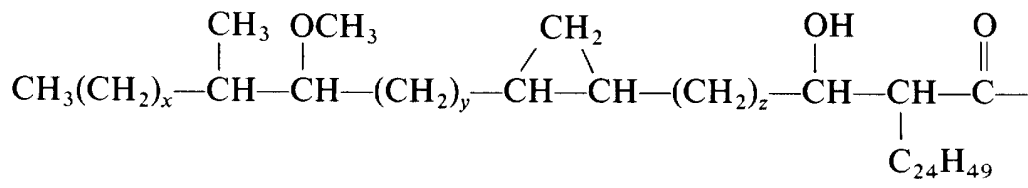

For the peaks at $m / z 1601$ and $1629, x+y+z=50,52$.

The spectrum of the $M$. leprae lipid (Fig. $5 b$ ) shows essentially only one principal series of peaks (derived from the sodium-cationized molecules) at $\mathbf{M}+23=1457,1485,1513,1541$ that correspond to trehalose esterified with a type I ('alpha') mycolate of the structure<smiles>CCCCCCCCCCCCCCCCCCC(O)C(CC)C(C)=O</smiles> 
in which $x+y+z=46,48,50,52$ (principal components 48,50 ). The alpha branch is $\mathrm{C}_{20} \mathrm{H}_{41}$ as described below. These results are in accord with those obtained by Draper et al. (1982) for the type I mycolic acids recovered from defatted cells of (armadillo-grown) $M$. leprae, with principal $x+y+z=48$. No other peaks definable with confidence can be recognized in our spectrum. $M$. leprae elaborates ketomycolates as well (Draper et al., 1982) but we did not detect them in our TMM.

\section{Characterization of the mycolate alpha branch: electron impact mass spectrometry}

The $M$. leprae TMM purified by HPLC as described above was directly hydrolysed to provide the free mycolic acid. The methyl ester (obtained with $\mathrm{CH}_{2} \mathrm{~N}_{2}$ ) was then examined by electron impact mass spectrometry. A principal spectrum was obtained at a temperature of about $260{ }^{\circ} \mathrm{C}$ in which a base (pyrolysis) peak was obtained at $m / z 354$ with a smaller peak at $m / z 382$; methylhexacosanoate $(m / z 410)$ was imperceptible. Therefore, the mycolate alpha branch of $M$. leprae $\mathrm{TMM}$ is principally a $\mathrm{C}_{20}$ constituent, which yields a methyldocosanoate during the pyrolytic cleavage, with a smaller complement of tetracosanoate generated from a $\mathrm{C}_{22}$ branch. Etemadi (1967) established that under the pyrolytic conditions in the vicinity of the probe holding the sample, methyl mycolates undergo a reverse Claisen reaction in which the alpha branch, the alpha carbon and the carbomethoxy group are eliminated cleanly as a methly ester whose size defines the alpha branch, viz.<smiles>[R]C(O)[C@H](CCC)C(=O)OC</smiles>

Our results are largely in agreement with those reported by Kusaka et al. (1981) (who, however, did not find evidence for $\mathrm{a}_{22} \alpha$-branch), by Asselineau et al. (1981), and by Draper et al. (1982), in whose studies both the $\mathrm{C}_{20}$ and $\mathrm{C}_{22} \alpha$-branches were described.

\section{Characterization of the sugar-ester bond}

As described in Methods, the TMM of M. leprae was permethylated, hydrolysed with alkali and the partially methylated trehalose recovered. By GLC it was found to be identical with authentic 2,3,4,6,2',3',4'-hepta-O-methyl trehalose prepared recently from semi-synthetic TMM (Liav \& Goren, 1986). Both samples had identical retention times (10.8-10.9 min). Authentic $2,3,4,2^{\prime}, 3^{\prime}, 4^{\prime}$-hexa- $O$-methyl trehalose (Goren et al., 1976) had a retention time of $15 \cdot 8$ min under the same conditions.

Acid hydrolysis of the hepta- $O$-methyl trehalose generated the two partially methylated glucose moieties. Their structures were determined by comparing them with authentic 2,3,4-triand 2,3,4,6-tetra- $O$-methyl glucose by GLC of the TMS derivatives. The following data were obtained:

\begin{tabular}{|c|c|c|c|c|}
\hline Sample (TMS derivatives) & \multicolumn{4}{|c|}{ Retention time (min) } \\
\hline $\begin{array}{l}\text { 2,3,4,6-Tetra- } O \text {-Me glucose } \\
\text { 2,3,4-Tri- } O \text {-Me glucose }\end{array}$ & 6.7, & & $8 \cdot 2$ & \\
\hline roducts from $M$. leprae TMM & 6.7, & $7 \cdot 3^{*}$ & $8 \cdot 2$ & 8 \\
\hline
\end{tabular}

Taken together with the results of mass spectrometry, these data prove that the glycolipid is a trehalose derivative acylated at a single 6-position with alpha (type I) mycolic acids bearing principally a $\mathrm{C}_{20}$ alpha branch, and therefore characteristic of $M$. leprae.

\section{DISCUSSION}

The sum of our evidence indicates that $M$. leprae synthesizes TMM in vivo. The most convincing evidence derives from the plasma desorption mass spectrum in which nearly exact 
molecular masses of the glycolipid are defined, from IR spectrophotometry, from the pattern of the HPLC elution, and from the permethylation studies.

We judge that the maximum amount of TMM that we recovered is probably no more than $400 \mu \mathrm{g}$ from $1 \mathrm{~g}$ (dry wt) of harvested $M$. leprae. In recent studies of $M$. microti cultured in vitro we recovered a minimum of $5 \mathrm{mg}$ TMM per $\mathrm{g}$ (dry wt) of bacteria and an abundance of TDM as well (unpublished results). The $M$. leprae lipids, however, contained no trace of TDM that we could detect. It is of course possible that a careful separation of a considerably larger gross lipid sample may allow TDM to be detected and perhaps isolated. We were also unable to detect any sulphatides ('sulpholipids') behaving like those of $M$. tuberculosis (these are also trehalose esters). Minnikin et al. (1985) also reported that their $M$. leprae sample did not contain either sulpholipids or TDM.

The minuscule quantity of TMM that we were able to recover would suggest that fulfilling of its probable anabolic role in cell wall biosynthesis almost exhausts the amount of this glycolipid that is available to the cell at any given time and, therefore, it may be unavailable for TDM biosynthesis. It is in accord with current observations respecting the precursor/product relationship between TMM and TDM that the cell's economy hardly allows for any diversion of such an important substance (TMM) into what may be a biosynthetic 'dead end'. Finally, we suggest that the identification of TMM in $M$. leprae secures for this glycolipid the distinction of being truly ubiquitous among mycobacteria.

This investigation was supported by Grant AI-08401 from the United States-Japan Cooperative Medical Science Program, administered by the National Institute of Allergy and Infectious Diseases. We thank Drs P. J. Brennan and P. Draper for samples of $M$. leprae lipids and Dr Kuni Takayama for HPLC separation of the $M$. leprae TMM. We thank Nadia de Stackelburg for illustrations and Ms Shirley Downs for careful preparation of the manuscript. M. B.G. is the Margaret Regan Investigator in Chemical Pathology, National Jewish Center for Immunology and Respiratory Medicine.

\section{REFERENCES}

Ahibo-Coffy, A., Aurelle, H., Lacave, C., Promé, J. C., Puzo, G. \& Savagnac, A. (1978). Isolation, structural studies and chemical synthesis of a palmitone lipid from Corynebacterium diphtheriae. Chemistry and Physics of Lipids 22, 185-195.

ARNARP, J. \& LöNNGREN, J. (1978). Alkylation of carbohydrates with alkyl trifluoromethanesulfonates. Acta chemica scandinavia B32, 465-467.

Asselineau, C. \& Asselineau, J. (1978). Trehalosecontaining glycolipids. Progress in the Chemistry of Fats and Other Lipids 16, 59-99.

Asselineau, C., Clavel, S., Clément, F., Daffé, M., David, H., LanéÈlle, M. A. \& Promé, J. C. (1981). Constituants lipidiques de Mycobacterium leprae isolé de tatou infecté experimentalement. Annales de microbiologie 132A, 19-30.

Azuma, S. \& YamamuRa, Y. (1963). Studies on the firmly bound lipids of human tubercle bacillus. II. Isolation of arabinose mycolate and identification of its chemical structure. Journal of Biochemistry 53, 275-281.

BRUNeteaU, M. \& Michel, G. (1968). Structure d'un dimycolate d'arabinose isolé de Mycobacterium marianum. Chemistry and Physics of Lipids 2, 229239.

Davidson, L. A., Draper, P. \& Minnikin, D. E. (1982). Studies on the mycolic acids from the walls of Mycobacterium microti. Journal of General Microbiology 128, 823-828.

Dhariwal, K. R., Dhariwal, G. \& Goren, M. B. (1984). Observations on the ubiquity of the Mycobacterium tuberculosis sulfatides in mycobacteria. American Review of Respiratory Diseases 130, 641-646.
DRAPER, P. (1976). Cell walls of Mycobacterium leprae. International Journal of Leprosy 44, 95-98.

DraPER, P. (1979). Annex 1, protocol 1/79. Report of the enlarged supervisory council meeting for research on the immunology of leprosy. Geneva: World Health Organization.

DRAPER, P. \& REes, R. J. W. (1973). The nature of the electron-transparent zone that surrounds $M y c o b a c-$ terium lepraemurium inside host cells. Journal of General Microbiology 77, 79-87.

DRAPER, P., Dobson, G., Minnikin, D. E. \& MinnIKIN, S. M. (1982). The mycolic acids of Mycobacterium leprae harvested from experimentally infected nine-banded armadillos. Annales de microbiologie 133B, 39-47.

ETEMADI, A. H. (1967). The use of pyrolysis gas chromatography and mass spectroscopy in the study of the structure of mycolic acids. Journal of Gas Chromatography 5, 447-456.

Folch, J., Lees, M. \& Sloane-Stanley, G. H. (1957). A simple method for isolation and purification of total lipids from animal tissues. Journal of Biological Chemistry 226, 497-509.

Gastambide-Odier, M. \& Lederer, E. (1964). Biosynthesis of corynomycolic acid from two molecules of palmitic acid. Nature, London 184, 1563-1564.

Gastambide-Odier, M., Delaumeny, J. M. \& LeDERER, E. (1964). Mise en évidence de cycles propaniques dans divers acides mycoliques de souche humaines et bovines de Mycobacterium tuberculosis. Comptes rendus hebdomadaires des séances de l'Académie des sciences 259, 3404-3407.

GOREN, M. B. (1970a). Sulfolipid I of Mycobacterium 
tuberculosis, strain H37Rv. I. Purification and properties. Biochimica et biophysica acta 210, 116126.

GOREN, M. B. (1970b). Sulfolipid I of Mycobacterium tuberculosis, strain H37Rv. II. Structural studies. Biochimica et biophysica acta 210, 127-138.

GoREN, M. B. \& BRENNAN, P. J. (1979). Mycobacterial lipids: chemistry and biologic activities. In Tuberculosis, pp. 63-193. Edited by G. P. Youmans. Philadelphia: W. B. Saunders.

GoReN, M. B. \& BROKL, O. (1974). Separation and purification of cord factor $\left(6,6^{\prime}\right.$-dimycoloyl trehalose) from wax $\mathrm{C}$ or from mycolic acids. Recent Results in Cancer Research 47, 251-258.

Goren, M. B., Brokl, O., Roller, P., Fales, H. M. \& DAS, B. C. (1976). Sulfatides of Mycobacterium tuberculosis: the structure of the principal sulfatide (SL-I). Biochemistry 15, 2728-2734.

Goren, M. B., BroKL, O. \& Roller, P. (1979). Cord factor (trehalose-6,6'-dimycolate) of in vivo-derived Mycobacterium lepraemurium. Biochimica et biophysica acta 574, 70-78.

Hunter, S. W. \& Brennan, P. J. (1981). A novel phenolic glycolipid from Mycobacterium leprae possibly involved in immunogenicity and pathogenicity. Journal of Bacteriology 147, 728-735.

Kanetsuna, F., Imaeda, T. \& CunTo, G. (1969). On the linkage between mycolic acid and arabinogalactan in phenol treated mycobacterial cell walls. Biochimica et biophysica acta 173, 341-344.

KATO, M. \& MAEDA, J. (1974). Isolation and biochemical activities of trehalose-6-monomycolate of $\mathrm{Myco}$ bacterium tuberculosis. Infection and Immunity 9, 814.

Kilburn, J. O., Takayama, K. \& Armstrong, E. L. (1982). Synthesis of trehalose dimycolate (cord factor) by a cell-free system of Mycobacterium smegmatis. Biochemical and Biophysical Research Communications 108, 132-139.

Kusaka, T, KoHSAKa, K., FukUnishi, Y. \& AKIMORI, H. (1981). Isolation and identification of mycolic acids in Mycobacterium leprae and Mycobacterium lepraemurium. International Journal of Leprosy 49, 406-416.

LEDERER, E. (1976). Cord factor and related trehalose esters. Chemistry and Physics of Lipids 16, 91-106.

LEDERER, E. (1984). Chemistry of mycobacterial cordfactor and related natural and synthetic trehalose esters. In The Mycobacteria. A Source Book, vol. 1, pp. 361-378. Edited by G. P. Kubica \& L. G. Wayne. New York: Marcel Dekker.

LIAV, A. \& GoREN, M. B. (1980). A new synthesis of cord factor and analogs. Chemistry and Physics of Lipids 27, 345-352.
Liav, A. \& Goren, M. B. (1984). Synthesis of 6-Omycoloyl- and 6- $O$-corynomycoloyl- $\alpha, \alpha$-trehalose. Carbohydrate Research 125, 323-328.

LiAv, A. \& GoREN, M. B. (1986). An improved synthesis of 6-O-mycoloyl- and 6-O-corynomycoloyl$\alpha, \alpha$-trehalose with observations on the permethylation analysis of trehalose glycolipids. Carbohydrate Research 154, (in the Press).

Macfarlane, R. D. (1983). Californium-252 plasma desorption mass spectrometry. Analytical Chemistry 55, 1247A-1264A.

MINNIKIN, D. E. (1982). Lipids: complex lipids, their chemistry, biosynthesis and roles. In The Biology of the Mycobacteria, vol. 1, pp. 95-184. Edited by C. Ratledge \& J. Stanford. London: Academic Press.

Minnikin, D. E., Dobson, G. \& Draper, P. (1985). The free lipids of Mycobacterium leprae harvested from experimentally infected nine-banded armadillos. Journal of General Microbiology 131, 2007-2011.

Nakamura, M., Itoh, T., Yoshitake, Y., SenguPTa, U. \& GOREN, M. B. (1984). Biochemical characteristics of $M$. lepraemurium propagated in cell-free liquid medium. International Journal of Leprosy 52, supplement no. 4, 720 .

NoLL, H. \& BLOCH, H. (1955). Studies on the chemistry of the cord factor of Mycobacterium tuberculosis. Journal of Biological Chemistry 214, 251-265.

Noll, H., Bloch, H., Asselineau, J. \& Lederer, E. (1956). The chemical structure of the cord factor of Mycobacterium tuberculosis. Biochimica et biophysica acta 20, 299-309.

Promé, J. C., Walker, R. W. \& Lacave, C. (1974). Condensation de deux molécules d'acide palmitique chez Corynebacterium diphtheriae: formation d'un $\beta$-ceto ester de tréhalose. Comptes rendus hebdomadaires des séances de l'Académie de sciences C218, 1065-1068.

TAKayama, K. \& Armstrong, E. L. (1976). Isolation, characterization and function of 6-mycoloyl-6'acetyltrehalose in the H37Ra strain of Mycobacterium tuberculosis. Biochemistry 15, 441-447.

TAKAYAMA, K. \& QURESHI, N. (1984) Structure and synthesis of lipids. In The Mycobacteria. A Source Book, vol. 1, pp. 361-378. Edited by G. P. Kubica \& L. G. Wayne. New York: Marcel Dekker.

Vilkas, E. \& Markovits, J. (1968). Isolement d'un digalactoside et d'un mycolate de diarabinoside a partir de cires D d'une souche humaine virulente de Mycobacterium tuberculosis. FEBS Letters 2, 20-22.

Walker, R. W., Promé, J. C. \& Lacave, C. (1973). Biosynthesis of mycolic acids. Formation of a $\mathrm{C}_{32}$ $\beta$-keto ester from palmitic acid in a cell-free system of Corynebacterium diphtheriae. Biochimica et biophysica acta 326, 52-62. 